\title{
Evaluation of Cisplatin Induced Toxicity in Head and Neck Cancer and Cervical Cancer During Concurrent Chemoradiotherapy. Experience of National Institute of Oncology in Morocco
}

\author{
Maghous $\mathrm{A}^{1 *}$, Marnouche $\mathrm{E}^{1}$, Loughlimi $\mathrm{H}^{\mathbf{1}}$, Rais $\mathrm{F}^{\mathbf{1}}$, Benhmidou $\mathbf{N}^{1}$, Adani-Ife $\mathbf{N}^{2}$, Elmajjaoui $\mathbf{S}^{1}$, Elkacemi $\mathrm{H}^{1}$, Kebdani $\mathrm{T}^{1}$ and Benjaafar $\mathbf{N}^{11}$ \\ ${ }^{1}$ Department of Radiotherapy, National Institute of Oncology, Mohammed V University in Rabat - Morocco \\ ${ }^{2}$ Department of Medical Oncology, National Institute of Oncology, Mohammed V University in Rabat - Morocco
}

\begin{abstract}
Background: Cisplatin is widely used as radio sensitizer in head and neck cancer (HNC) and cervical cancer. We conducted this prospective study to evaluate cisplatin induced toxicity as once-weekly regimen in HNC and cervical cancer during concurrent chemoradiotherapy (CCRT) to optimize its administration.

Patients and methods: From 01 January 2015 to 11 May 2015, a data of all eligible patients treated by chemoradiation regimens containing a low dose of cisplatin were collected at the Department of radiotherapy in National Institute of Oncology in Morocco. Cisplatin was used weekly at $40 \mathrm{mg} / \mathrm{m} 2$ with adequate hydration and premedication in all patients. A complete blood count and renal function tests were done prior to each cycle of chemotherapy to evaluate toxicity according to the National Cancer Institute Common Terminology Criteria for Adverse Events ( $\mathrm{NCl} \mathrm{CTCAE,} \mathrm{version} \mathrm{4.0).}$

Results: A total of 96 patients were eligible for the analysis. Mean age, PS, initial weight, enteral nutrition, cisplatin mean dose, use of oral Ondansetron and baseline serum tests did not differ significantly among the types of malignancy. However, weight loss was significantly noted among HNC group compared to cervical cancer patients with $6.06 \pm 2.92 \mathrm{~kg}$ and $0.02 \pm 0.13 \mathrm{~kg}$ respectively. Toxicity was observed only in $16(20 \%)$ patients after the 4 th week of treatment especially among HNC group. The neutropenia and thrombocytopenia were significantly greater for patients of HNC. However, we did not observe any renal toxicity, thrombocytopenia and $\geq$ grade 3 neutropenia toxicity in cervical cancer group. In multivariated analysis, only a subtype of $\mathrm{HNC}$ (OR, 1233; 95\% Cl, 16-95 103; $\mathrm{P}=0.001)$ and grade 2 emetogenicity $(\mathrm{OR}, 34.8 ; 95 \% \mathrm{Cl}, 2.1-583 ; \mathrm{P}=0.014)$ were significantly associated with an increased risk for cisplatin toxicity. Whereas, less than 4 weekly cisplatin treatment $(\mathrm{OR}, 0.4 ; 95 \% \mathrm{Cl}, 0.1-0.9$; $\mathrm{P}=0.046$ ) was associated with a significantly reduced risk.
\end{abstract}

Conclusion: Our data have revealed that individuals with $\mathrm{HNC}$ were at a significantly higher risk for cisplatininduced toxicity during CCRT and suggest that the once-weekly smaller dose of cisplatin regimen and conventional prophylactic procedures of administration might be effective for protection against the renal toxicity of cisplatin.

Keywords: Cisplatin toxicity; Concurrent chemoradiotherapy; Head and neck cancer; Cervical cancer

Abbreviations: HNC: Head and Neck Cancer; CCRT: Concurrent Chemoradiotherapy; NCI CTCAE: National Cancer Institute Common Terminology Criteria for Adverse Events; PS: Performance Status; NSAIDs: Non-Steroidal Anti-Inflammatory Drugs; SD: Standard Deviation; IQR: Interquartile Range; CC: Creatinine Clearance; RT: Radiation Therapy

\section{Background and Introduction}

Cisplatin or cis-diamminedichloroplatinum (II) is a highly effective chemotherapeutic drug whose anticancer activity was accidentally discovered by the physicist-biologist Barnett Rosenberg [1]. Then, it has been used as a major antineoplastic drug for the treatment of diverse solid tumors [2]. However, the efficacy of cisplatin is limited by severe side effects, dose dependent, such as renal toxicity, hematologic toxicity and emetogenicity $[3,4]$.

Cisplatin is a potent radiosensitizer and the drug most commonly used for chemoradiotherapy in various inoperable locally advanced solid tumors [5-7]. Chemoradiation showed significant benefit for local recurrence and for distant recurrence [8-10]. Thus, cisplatinbased chemoradiation was largely accepted as the standard of care for patients with head and neck cancer (HNC) and cervical cancer. The standard chemoradiation regimens containing a low dose of cisplatin with aggressive hydration might reduce its toxicity.

The aim of this prospective study is to evaluate cisplatin induced toxicity as once-weekly regimen in HNC and cervical cancer during concurrent chemoradiotherapy (CCRT) to optimize its administration.

\section{Patients and Methods}

\section{Population and study sites}

This prospective study was conducted during the period from 01 January 2015 to 11 May 2015 at the Department of radiotherapy in

*Corresponding author: Maghous A, Department of Radiotherapy, Nationa Institute of Oncology, Mohammed $\vee$ University in Rabat, Morocco, Tel: +2237199028; E-mail: magabdelhak@gmail.com

Received January 17, 2017; Accepted January 27, 2017; Published January 31 2017

Citation: Maghous A, Marnouche E, Loughlimi H, Rais F, Benhmidou N, et al. (2017) Evaluation of Cisplatin Induced Toxicity in Head and Neck Cancer and Cervical Cancer During Concurrent Chemoradiotherapy. Experience of National Institute of Oncology in Morocco. J Cancer Sci Ther 9: 314-318. doi: 10.4172/1948-5956.1000434

Copyright: () 2017 Maghous A, et al. This is an open-access article distributed under the terms of the Creative Commons Attribution License, which permits unrestricted use, distribution, and reproduction in any medium, provided the original author and source are credited. 
Citation: Maghous A, Marnouche E, Loughlimi H, Rais F, Benhmidou N, et al. (2017) Evaluation of Cisplatin Induced Toxicity in Head and Neck Cancer and Cervical Cancer During Concurrent Chemoradiotherapy. Experience of National Institute of Oncology in Morocco. J Cancer Sci Ther 9 : 314-318. doi: 10.4172/1948-5956.1000434

National Institute of Oncology in Morocco. During that time, a clinical and biological data of all patients treated by chemoradiation regimens containing a low dose $\left(40 \mathrm{mg} / \mathrm{m}^{2}\right)$ of cisplatin were collected after obtaining oral consent from each patient. Patients were eligible if they had a correct laboratory tests and had an Eastern Cooperative Oncology Group performance status (PS) of 0 or 1 . Patients were excluded from the study if they had a history of neoadjuvant chemotherapy, more than one cancer, uncontrolled intercurrent illness, obstructive uropathy or nephrotoxic treatment used during chemoradiation such as some antihypertensive or non-steroidal anti-inflammatory drugs (NSAIDs).

\section{Cisplatin administration}

Cisplatin-based chemoradiation was used in our department weekly at $40 \mathrm{mg} / \mathrm{m}^{2}$ with a maximum of $70 \mathrm{mg}$ per cycle. It was administered in $500 \mathrm{~mL}$ of $0.9 \%$ normal saline over 30 minute. All patients were pre hydrated with $1 \mathrm{~L}$ of $0.9 \%$ normal saline and post hydrated with $1 \mathrm{~L}$ of $0.9 \%$ normal saline, which was administered over $1 \mathrm{~h}$. Oral hydration with 2 - $3 \mathrm{~L}$ the night before and the day after treatment was recommended for all patients. Antiemetic prophylaxis with 5-HT3 serotonin receptor antagonists (Ondansetron) plus methylprednisolone was administered $15 \mathrm{~min}$ before the onset of chemotherapy in all cases. A supplemented oral antiemetic treatment during the 3 days was prescribed for all patients.

\section{Toxicity evaluation}

Complete blood count and renal function tests were done prior to each cycle of chemotherapy.

Nephrotoxicity indicating the postponement of the treatment was defined as a creatinine clearance (CC) less than $50 \mathrm{ml} / \mathrm{min}$ according to the Cockcroft-Gault equation or $50 \mathrm{ml} / \mathrm{min} / 1.73 \mathrm{~m}^{2}$ by MDRD eGFR for patients over 65 years. Nephrotoxicity was also defined as an increase in the serum creatinine concentration of grade 2 or higher, according to the National Cancer Institute Common Terminology Criteria for Adverse Events (NCI CTCAE, version 4.0).

According to the same criteria, anemia was noted grade 2 when the hemoglobin $(\mathrm{Hb})$ is less than $10.0-8.0 \mathrm{~g} / \mathrm{dl}$ and grade 3 indicating a transfusion; when $\mathrm{Hb}$ is lower than $8.0-6.5 \mathrm{~g} / \mathrm{dl}$. Neutropenia was noted grade 2 when the neutrophil rate is $<1500-1000 / \mathrm{mm}^{3}$, grade 3 if $<1000-500 / \mathrm{mm}^{3}$ and grade 4 if $<500 / \mathrm{mm}^{3}$. Thrombocytopenia was noted grade 1 when the platelet count is $<150,000-75,000 / \mathrm{mm}^{3}$ and grade 2 if $<75,000-50,000 / \mathrm{mm}^{3}$, whereas, we practically postponed the treatment when the platelet count is less than $100,000 / \mathrm{mm}^{3}$. Finally, vomiting was noted grade 1 when the patients report between 1 to 2 episodes (separated by 5 minutes) in 24 hours and grade 2 between 3 to 5 episodes (separated by 5 minutes) in 24 hours, while an increase of 4-6 stools per day over baseline was noted grade 2 diarrhea.

\section{Statistical analysis}

Statistical analysis of the data was carried out by the SPSS 13.0 for Windows (SPSS, Inc., Chicago, IL, USA). Qualitative variables were presented as number and percentages. Quantitative variables were presented as mean \pm standard deviation (SD) for variables with normal distribution, and as median and interquartile range (IQR) for variables with skewed distributions. $\mathrm{Chi}^{2}$ tests and Fisher test were used to identify cisplatine-induced toxicity associated with tumor type. A multivariate logistic regression was used to determine clinicopathologic factors associate with biological cisplatine toxicity. In all tests, the values $\mathrm{p}<0.05$ were regarded statistically significant

\section{Results}

\section{Patient characteristics}

A total of 96 patients who received weekly cisplatin-based chemoradiation were eligible for the analysis. Baseline characteristics of the eligible patients are summarized in Table 1 . The mean age was $52.7 \pm 12.5$ years (range, 20-96), and most patients were female $(83.3 \%)$ and had a good PS of $0(82.3)$ or $1(17.7 \%)$. The tumor type was cervical cancer (64.6\%) and HNC (35.4\%) with predominance of nasopharyngeal cancer $(61.8 \%)$.

Mean age, PS, initial weight, enteral nutrition, cisplatin mean dose, use of preventing oral Ondansetron, baseline serum creatinine concentration, baseline creatinine clearance (CC), baseline neutrophil rate and platelet count did not differ significantly among the types of malignancy. However, weight loss was significantly noted among HNC group compared to cervical cancer patients with $6.06 \pm 2.92 \mathrm{~kg}$ and 0.02 $\pm 0.13 \mathrm{~kg}$ respectively at the end of treatment. In terms of estimated oral hydration of the patients during CCRT, it was significantly lower in patients of HNC as compared to cervical cancer $(\mathrm{P}<0.001)$.

\section{Cisplatin-induced toxicity}

The cisplatin-induced toxicity according to grade and tumor types is shown in Table 2 . We observed 53 vomiting toxicity, essentially grade $1(37.5 \%)$ and grade $2(17.7 \%)$. In terms of biological toxicity, we observed one patient with grade 3 renal toxicity, one patient in each group with grade 3 anemia toxicity, thirteen patients with $\geq$ grade 2 neutropenia and five with thrombocytopenia. The neutropenia and thrombocytopenia toxicity were significantly greater for patients of $\mathrm{HNC}$ with $\mathrm{P}<0.001$ and $\mathrm{P}=0.005$ respectively. We did not observe any renal toxicity, thrombocytopenia and $\geq$ grade 3 neutropenia toxicity in cervical cancer group. The two groups of patients did not differ in terms of emetogenicity, nephrotoxicity and anemia.

The time of recorded biological toxicity is shown in Table 3. All of toxicity is shown after the fourth week of treatment especially among HNC group.

\section{Clinico-pathologic analysis of risk factors for biological cisplatin toxicity}

Cisplatin-induced toxicity was observed in $16(20 \%)$ of the 96 eligible patients. To assess the contribution of each individual risk factor to cisplatin-induced toxicity, we performed univariate and multivariate logistic regression analysis (Table 4$)$. In univariate analysis, female sex (OR, 6.14; 95\% CI, 1.83-20.51; P=0.003), subtype of HNC (OR, 48.16; 95\% CI, 5.96-388.85; $\mathrm{P}<0.001$ ), grade 2 emetogenicity (OR, 9.33; 95\% CI, 2.04-42.66; $\mathrm{P}=0.004)$ and weight loss (OR, 1.33; 95\% CI, 1.14$1.56 ; \mathrm{P}<0.001)$ were significantly associated with an increased risk for cisplatin toxicity. In multivariate analysis, only a subtype of HNC (OR, 1233; 95\% CI, 16-95 103; $\mathrm{P}=0.001)$ and grade 2 emetogenicity (OR, 34.8; 95\% CI, 2.1-583; $\mathrm{P}=0.014$ ) were significantly associated with an increased risk for cisplatin toxicity whereas, less than 4 weekly cisplatin treatment (OR, 0.4; 95\% CI, 0.1-0.9; $\mathrm{P}=0.046)$ was associated with a significantly reduced risk. No significant differences were found among the other variables studied.

\section{Discussion}

Cisplatin is a potent radiosensitizer and the drug most commonly used for chemoradiotherapy in locoregionally advanced cervical cancer and HNC despite of its severe toxic effects, such as nephro-, hemato- and ototoxic effects, nausea and vomiting, as well as severe mucositis, which 
Citation: Maghous A, Marnouche E, Loughlimi H, Rais F, Benhmidou N, et al. (2017) Evaluation of Cisplatin Induced Toxicity in Head and Neck Cancer and Cervical Cancer During Concurrent Chemoradiotherapy. Experience of National Institute of Oncology in Morocco. J Cancer Sci Ther 9 : 314-318. doi: 10.4172/1948-5956.1000434

\begin{tabular}{|c|c|c|c|c|}
\hline Characteristics & All patients & Cervical cancer & Head and neck cancer & $P$ value \\
\hline & $\mathrm{n}=96$ & $n=62$ & $n=34$ & $<0.001$ \\
\hline \multicolumn{5}{|c|}{$\operatorname{Sex}^{\circ}$} \\
\hline Male & $16(16.7)$ & - & $16(47.1)$ & \multirow[b]{3}{*}{0.741} \\
\hline Female & $80(83.3)$ & $62(100)$ & $18(52.9)$ & \\
\hline Age (years) ${ }^{*}$ & $52.7 \pm 12.5$ & $53 \pm 12.7$ & $52.2 \pm 12.2$ & \\
\hline \multicolumn{5}{|c|}{$\mathbf{P S}^{\circ}$} \\
\hline 0 & 79 (82.3) & $52(83.9)$ & $27(79.4)$ & \multirow{2}{*}{0.584} \\
\hline 1 & $17(17.7)$ & $10(16.1)$ & $7(20.6)$ & \\
\hline Initial weight $(\mathrm{kg})^{*}$ & $64.9 \pm 13.9$ & $64.4 \pm 14.6$ & $65.9 \pm 12.8$ & 0.611 \\
\hline Weight loss during treatment $(\mathrm{kg})^{\star}$ & $2.16 \pm 3.38$ & $0.02 \pm 0.13$ & $6.06 \pm 2.92$ & $<0.001$ \\
\hline Total weekly Cisplatin treatment ${ }^{*}$ & $4.8 \pm 1$ & $4.3 \pm 0.6$ & $5.7 \pm 0.9$ & $<0.001$ \\
\hline Cisplatin mean dose $\left(\mathrm{mg} / \mathrm{m}^{2}\right)^{*}$ & $64.8 \pm 5.7$ & $64.4 \pm 5.1$ & $65.5 \pm 6.7$ & - \\
\hline Enteral Nutrition $^{\circ}$ & $96(100)$ & $34(100)$ & $62(100)$ & - \\
\hline \multicolumn{5}{|c|}{ Estimated oral hydration $(\mathrm{ml} / \mathrm{day})^{\circ}$} \\
\hline$<1000$ & $70(72.9)$ & $36(58.1)$ & $34(100)$ & \multirow[b]{3}{*}{0.364} \\
\hline $1000-2000$ & $21(21.9)$ & $21(33.9)$ & $0(0)$ & \\
\hline$\geq 2000$ & $5(5.2)$ & $5(3.1)$ & $0(0)$ & \\
\hline \multicolumn{5}{|c|}{ Preventing oral Ondansetron ${ }^{\circ}$} \\
\hline Yes & $64(71.1)$ & $42(70)$ & $22(73.3)$ & \multirow{2}{*}{0.822} \\
\hline No & $26(28.9)$ & $18(30)$ & $8(26.6)$ & \\
\hline Baseline creatinine concentration $\left(\mathrm{mg} / \mathrm{l}^{*}\right.$ & $6.7 \pm 1$ & $6.5 \pm 0.8$ & $6.9 \pm 1.3$ & 0.051 \\
\hline Baseline creatinine clearance $(\mathrm{CC})^{*}$ & $114.7 \pm 29.5$ & $112.4 \pm 30.3$ & $118.8 \pm 27.9$ & 0.318 \\
\hline Baseline hemoglobin rate $(\mathrm{g} / \mathrm{dl})^{*}$ & $12.6 \pm 1.4$ & $12.3 \pm 1.4$ & $13.2 \pm 1.2$ & 0.001 \\
\hline Baseline neutrophil rate $/ \mathrm{mm}^{3} \$$ & $4455(3322 ; 6600)$ & $4480(3579 ; 6755)$ & $4273(3018 ; 6560)$ & 0.220 \\
\hline Baseline platelet count $/ \mathrm{mm}^{3} \$$ & $290(237 ; 357)$ & $297(237,367)$ & $274(230 ; 342)$ & 0.387 \\
\hline
\end{tabular}

Table 1: Baseline characteristics of the study patients.

\begin{tabular}{|c|c|c|c|c|}
\hline Toxicity & All patients & Cervical cancer & Head and neck cancer & $P$ value \\
\hline & $n=96$ & $n=62$ & $n=34$ & \\
\hline \multicolumn{5}{|c|}{ Emetogenicity } \\
\hline Grade 1 & $36(37.5)$ & $23(37.1)$ & $13(38.2)$ & 0.816 \\
\hline Grade 2 & $17(17.7)$ & $10(16.1)$ & $7(20.6)$ & \\
\hline \multicolumn{5}{|l|}{ Nephrotoxicity } \\
\hline Grade 2 & $0(0)$ & $0(0)$ & $0(0)$ & 0.354 \\
\hline Grade 3 & $1(1)$ & $0(0)$ & $1(2.9)$ & \\
\hline \multicolumn{5}{|c|}{ Hematotoxicity } \\
\hline \multicolumn{5}{|c|}{ Anemia } \\
\hline Grade 2 & $11(11.5)$ & $5(8.1)$ & $6(17.6)$ & 0.290 \\
\hline Grade 3 & $2(2.1)$ & $1(1.6)$ & $1(2.9)$ & \\
\hline \multicolumn{5}{|c|}{ Neutropenia } \\
\hline Grade 2 & $9(9.4)$ & $1(1.6)$ & $8(23.5)$ & $<0.001$ \\
\hline Grade 3 & $3(3.1)$ & $0(0)$ & $3(8.8)$ & \\
\hline Grade 4 & $1(1)$ & $0(0)$ & $1(2.9)$ & \\
\hline \multicolumn{5}{|c|}{ Thrombocytopenia } \\
\hline Grade 1 & $4(4.2)$ & $0(0)$ & $4(11.8)$ & 0.005 \\
\hline Grade 2 & $1(1)$ & $0(0)$ & $1(2.9)$ & \\
\hline
\end{tabular}

Table 2: Cisplatine toxicity grade among patient's groups.

\begin{tabular}{|c|c|c|c|}
\hline Biological toxicity time & All patients & Cervical cancer & Head and neck cancer \\
\hline & $n=16$ & $n=1$ & $n=15$ \\
\hline After $4^{\text {th }}$ treatment & $3(18.8)$ & $1(100)$ & $2(13.3)$ \\
\hline After $5^{\text {th }}$ treatment & $7(43.8)$ & $0(0)$ & $7(46.7)$ \\
\hline After $6^{\text {th }}$ treatment & $6(37.5)$ & $0(0)$ & $6(40)$ \\
\hline
\end{tabular}

Table 3: Time of recorded biological toxicity. 
Citation: Maghous A, Marnouche E, Loughlimi H, Rais F, Benhmidou N, et al. (2017) Evaluation of Cisplatin Induced Toxicity in Head and Neck Cancer and Cervical Cancer During Concurrent Chemoradiotherapy. Experience of National Institute of Oncology in Morocco. J Cancer Sci Ther 9 : 314-318. doi: 10.4172/1948-5956.1000434

\begin{tabular}{|c|c|c|c|c|c|c|c|c|}
\hline \multirow[t]{2}{*}{ Characteristics } & \multicolumn{2}{|c|}{ Biological cisplatin toxicity } & \multicolumn{3}{|c|}{ Bivariated Analysis } & \multicolumn{3}{|c|}{ Multivariated Analysis } \\
\hline & Yes $(n=16)$ & No $(n=80)$ & OR & $95 \% \mathrm{Cl}$ & $P$ value & OR & $95 \% \mathrm{Cl}$ & $P$ value \\
\hline Age (years) & $54 \pm 11.6$ & $52.5 \pm 12.7$ & 1.01 & $0.967-1.05$ & 0.651 & & & \\
\hline \multicolumn{9}{|c|}{ Sex } \\
\hline Male & $7(43.8)$ & $9(11.2)$ & 1(Ref) & & & & & \\
\hline Female & $9(56.2)$ & $71(88.8)$ & 6.14 & $1.83-20.51$ & 0.003 & 1.5 & $0.18-12.7$ & 0.692 \\
\hline \multicolumn{9}{|c|}{ Tumor type } \\
\hline Cervical & $1(6.2)$ & $61(76.2)$ & 1(Ref) & & & & & \\
\hline Head and neck & $15(93.8)$ & $19(23.8)$ & 48.16 & $5.96-388.85$ & $<0.001$ & 1233 & $16-9510^{3}$ & 0.001 \\
\hline \multicolumn{9}{|c|}{ PS } \\
\hline 0 & $13(81.2)$ & $66(82.5)$ & 1(Ref) & & & & & \\
\hline 1 & $3(18.8)$ & $14(17.5)$ & 1.09 & $0.27-4.33$ & 0.905 & & & \\
\hline \multicolumn{9}{|c|}{ Estimated oral hydration (ml/day) } \\
\hline$<1000$ & $16(100)$ & $54(67.5)$ & $4710^{7}$ & $0-<0.001$ & 0.999 & & & \\
\hline $1000-2000$ & $0(0)$ & $21(26.2)$ & 1 & $0-<0.001$ & 1 & & & \\
\hline$\geq 2000$ & $0(0)$ & $5(6.2)$ & 1(Ref) & & & & & \\
\hline Total weekly treatment & $5.3 \pm 0.8$ & $4.7 \pm 1$ & 1.65 & $0.98-2.78$ & 0.060 & 0.4 & $0.1-0.9$ & 0.046 \\
\hline \multicolumn{9}{|c|}{ Emetogenicity } \\
\hline No. & $3(18.8)$ & $40(50)$ & 1(Ref) & & & & & \\
\hline Grade 1 & $6(37.5)$ & $30(37.5)$ & 2.67 & $0.617-11.53$ & 0.189 & 2 & $0.3-13$ & 0.468 \\
\hline Grade 2 & $7(43.8)$ & $10(12.5)$ & 9.33 & $2.04-42.66$ & 0.004 & 34.8 & $2.1-583$ & 0.014 \\
\hline Weight loss during treatment $(\mathrm{kg})$ & $5.3 \pm 3$ & $1.5 \pm 3.1$ & 1.33 & $1.14-1.56$ & $<0.001$ & 0.9 & $0.7-1.2$ & 0.510 \\
\hline Cisplatin mean dose $\left(\mathrm{mg} / \mathrm{m}^{2}\right)$ & $66.2 \pm 8.3$ & $64.5 \pm 5$ & 1.05 & $0.96-1.16$ & 0.278 & 1 & $0.8-1.2$ & 0.795 \\
\hline
\end{tabular}

Abbreviations: OR=Odds Ratio, $95 \mathrm{Cl}=95 \%$ Confidence Interval.

Table 4: Comparison of clinicopathologic characteristics as risk factors for cisplatin-induced toxicity.

make the treatment suitable only for patients with normal CC and a good PS. In the present study, we found that $20 \%(16 / 96)$ of individuals who received weekly cisplatin at a dose of $40 \mathrm{mg} / \mathrm{m}^{2}$ developed acute toxicity after 4 th week of planned treatment, especially in HNC group, despite the adoption of conventional measures of hydration and smaller cisplatin dose. That side effect includes low grade of neutropenia, thrombocytopenia and only one case of reversible grade 3 renal toxicity. These results indicate that the once-weekly smaller dose of cisplatin regimen and conventional prophylactic procedures of administration were sufficient to prevent toxic effects essentially renal toxicity in most our patients.

Concurrent administration of $100 \mathrm{mg} / \mathrm{m}^{2}$ cisplatin once every 3 weeks and radiation therapy (RT) has been extensively studied and was the only evidence-based cisplatin regimen available for CCRT for locoregionally advanced HNC [11,12]. However, to limit toxic effects, large-scale randomized trials used alternative regimen, such as weekly cisplatine administration during RT [13-16]. Schedules that deliver weekly cisplatin in smaller doses seem to be considerably less toxic without compromising efficacy. To date, weekly cisplatin $(40 \mathrm{mg} /$ $\mathrm{m}^{2}$ ) during RT is the optimal chemotherapy schedule in the treatment of cervical cancer. Moreover, this regimen has significantly improved compliance and reduced acute toxicity, while not affecting response and survival rates, compared to cisplatin plus 5 -fluorouracil (5-FU) regimen [17]. Based on these results, a combination of weekly $40 \mathrm{mg} / \mathrm{m}^{2}$ cisplatin and RT was adopted as a routine regimen in our institution.

In our experience, weekly cisplatin of $40 \mathrm{mg} / \mathrm{m}^{2}$ combined with RT given either as definitive or postoperative treatment was accompanied by only one patient with grade 3 renal toxicity, two patients with grade 3 anemia toxicity, thirteen patients with $\geq$ grade 2 neutropenia and five with thrombocytopenia. We observed no serious nephrotoxicity, ototoxicity, or neurotoxicity. These findings demonstrate that smaller individual doses of cisplatin may lead to less chemotherapy-induced morbidity when a prophylactic procedure of its administration is respected. Good tolerance of this alternative cisplatin dosing schedules has also been reported in multiple large randomized trials in locally advanced HNC $[15,16]$ as well as in cervical cancer $[17,18]$, because it resulted in a higher rate of completion of chemoradiation and less serious (grade 3/4) renal and hematologic toxicity. Additionally, more frequent cisplatine administration could provide radiosensitizing chemotherapy as a larger proportion of the administered RT dose. Therefore, concomitant weekly cisplatin with RT is a safe and effective treatment regimen.

To assess the potential risk factors for cisplatin-induced toxicity, we performed multivariable logistic regression analyses. Consistent with previous results [19] we found that individuals with HNC were at a significantly higher risk for cisplatin-induced toxicity than were those with cervical cancer, strongly for neutropenia and thrombocytopenia. Whereas, less than 4 weekly cisplatin treatment was associated with a significantly reduced risk. Regarding tumor type, and despite of the mean dosage of cisplatin in patients with $\mathrm{HNC}$ was $65.5 \pm 6.7 \mathrm{mg}$, which was not significantly higher than that of cervical cancer $(64.4 \pm$ $5.1 \mathrm{mg}$ ), such an association can be explained primarily by the higher number of weekly cisplatin planned treatment, the lower estimated oral hydration, the weight loss during treatment and the serious vomiting toxicity among HNC group. During CCRT, as the 4 th week is reached, a cumulative dose of cisplatin increased, leading to serious vomiting and more severe oral mucosal reactions that affect oral intake, which further add to the cisplatin-induced toxicity [20]. In this study, all of toxicity is shown after the 4 th week of treatment, and found significantly lower estimated oral hydration now in HNC patients as compared to cervical cancer $(\mathrm{P}<0.001)$. In cervical cancer without obstructive uropathy, cisplatin-induced toxicity is less severe as oral intake of water and liquid is not much impaired. A multivariable analysis showed significantly association between grade 2 vomiting and increased risk for cisplatin toxicity $(\mathrm{P}=0.014)$. Nonhematologic cisplatine toxicities, including nausea, vomiting, and mucositis, might be associated with an increased risk for cisplatin-induced hematologic toxicity [4]. 
Citation: Maghous A, Marnouche E, Loughlimi H, Rais F, Benhmidou N, et al. (2017) Evaluation of Cisplatin Induced Toxicity in Head and Neck Cancer and Cervical Cancer During Concurrent Chemoradiotherapy. Experience of National Institute of Oncology in Morocco. J Cancer Sci Ther 9 : 314-318. doi: 10.4172/1948-5956.1000434

The present study had certain notable limitations. First, patients were eligible of study if they had a good PS, correct baseline laboratory test and without co morbidity which is not valid for all patients. Second, many patients did not receive the full planned cisplatin dose owing to various factors not related to toxicity such as administrative problems.

\section{Conclusion}

In conclusion, our data have revealed that individuals with HNC were at a significantly higher risk for cisplatin-induced toxicity during CCRT, that toxicity is shown after the 4 th week of planned treatment when oral mucosal reactions increase and affect oral intake. Our findings also suggest that the once-weekly smaller dose of cisplatin regimen and conventional prophylactic procedures of administration might be effective for protection against cisplatin toxicity essentially renal toxicity.

\section{Funding}

Special thanks are due to the Faculty of Medicine and Pharmacy of Rabat; the source(s) of funding for all authors

\section{Authors' Contributions}

A.M., collected the clinical data, performed research, and analyzed data statistically; E.M., F.R., N.B., H.L., and S.A. contribute to collection of clinical data; S.E, H.E., T.E., and N.B., designed and coordinated research and drafted the manuscript. All authors read and approved the final manuscript.

\section{Acknowledgements}

The authors acknowledge the National Institute of Oncology (INO), for support in collecting the data and providing the research facilities. Special thanks are due to the School of Medicine and Pharmacy of Rabat; the source(s) of funding for all authors.

\section{References}

1. Rosenberg B, Van Camp L, Trosko JE, Mansour VH (1969) Platinum compounds: A new class of potent antitumour agents. Nature 222: 385-386.

2. Rozencweig M, Von Hoff DD, Slavik M, Muggia FM (1977) Cisdiamminedichloroplatinum (II). A new anticancer drug. Ann Intern Med 86: 803-812.

3. Wang D, Lippard SJ (2005) Cellular processing of platinum anticancer drugs Nat Rev Drug Discov 4: 307-320.

4. Pabla N, Dong Z (2008) Cisplatin nephrotoxicity: Mechanisms and renoprotective strategies. Kidney Int 73: 994-1007.

5. Boeckman HJ, Trego KS, Turchi JJ (2005) Cisplatin sensitizes cancer cells to ionizing radiation via inhibition of nonhomologous end joining. Mol Cancer Res 3: 277-285.

6. Marcu L, Bezak E, Olver I (2006) Scheduling cisplatin and radiotherapy in the treatment of squamous cell carcinomas of the head and neck: A modelling approach. Phys Med Biol 51: 3625-3637.
7. Marcu L, Van Doorn T, Olver I (2003) Cisplatin and radiotherapy in the treatment of locally advanced head and neck cancer-a review of their cooperation. Acta Oncol 42: 315-325.

8. Rose PG, Bundy BN, Watkins EB, Thigpen JT, Deppe G, et al. (1999) Concurrent cisplatin-based radiotherapy and chemotherapy for locally advanced cervical cancer. N Engl J Med 340: 1144-1153.

9. Chemoradiotherapy for Cervical Cancer Meta-analysis Collaboration (CCCMAC) (2010) Reducing uncertainties about the effects of chemoradiotherapy fo cervical cancer: individual patient data meta-analysis. Cochrane Database Syst Rev CD008285.

10. Pignon JP, Le Maître A, Maillard E, Bourhis J, MACH-NC Collaborative Group (2009) Meta-analysis of chemotherapy in head and neck cancer (MACH-NC) an update on 93 randomised trials and 17,346 patients. Radiother Oncol 92: 4-14.

11. Cooper JS, Pajak TF, Forastiere AA, Jacobs J, Campbell BH, et al. (2004) Postoperative concurrent radiotherapy and chemotherapy for high-risk squamous-cell carcinoma of the head and neck. N Engl J Med 350: 1937-1944.

12. Bernier J, Domenge C, Ozsahin M, Matuszewska K, Lefebvre JL, et al. (2004) Postoperative irradiation with or without concomitant chemotherapy for locally advanced head and neck cancer. N Engl J Med 350:1945-1952.

13. Bachaud JM, Cohen-Jonathan E, Alzieu C, David JM, Serrano E, et al. (1996) Combined postoperative radiotherapy and weekly cisplatin infusion for locally advanced head and neck carcinoma: final report of a randomized trial. Int J Radiat Oncol Biol Phys 36:999.

14. Traynor AM, Richards GM, Hartig GK, Khuntia D, Cleary JF, et al. (2010) Comprehensive IMRT plus weekly cisplatin for advanced head and neck cancer: the University of Wisconsin experience. Head Neck 32: 599-606.

15. Newlin HE, Amdur RJ, Riggs CE, Morris CG, Kirwan JM, et al. (2010) Concomitant weekly cisplatin and altered fractionation radiotherapy in locally advanced head and neck cancer. Cancer 116: 4533.

16. Sharma A, Mohanti BK, Thakar A, Bahadur S, Bhasker S (2010) Concomitan chemoradiation versus radical radiotherapy in advanced squamous cel carcinoma of oropharynx and nasopharynx using weekly cisplatin: A phase II randomized trial. Ann Oncol 21: 2272

17. Kim YS, Shin SS, Nam JH, Kim YT, Kim YM, et al. (2008) Prospective randomized comparison of monthly fluorouracil and cisplatin versus weekly cisplatin concurrent with pelvic radiotherapy and high-dose rate brachytherapy for locally advanced cervical cancer. Gynecol Oncol 108: 195.

18. Ang KK (2004) Concurrent radiation chemotherapy for locally advanced head and neck carcinoma: are we addressing burning subjects? J Clin Oncol 22: 4657.

19. Bagri PK, Kapoor A, Kalwar A, Singhal MK, Singh D, et al. (2014) Comparative analysis of cisplatin-induced nephrotoxicity in head and neck cancer and carcinoma cervix during concurrent chemoradiotherapy. South Asian Journal of Cancer 3: 217-220.

20. Mallick S, Benson R, Rath GK (2016) Radiation induced oral mucositis: a review of current literature on prevention and management. Eur Arch Otorhinolaryngo 273: $2285-2293$ 